\title{
Energy relations of winter roost-site utilization by American goldfinches (Carduelis tristis)
}

\author{
William A. Buttemer* \\ Division of Biological Sciences, The University of Michigan, Ann Arbor, MI 48103, USA
}

\begin{abstract}
Summary. American goldfinches (Carduelis tristis) were observed roosting in Colorado blue spruce (Picea pungens), which comprised part of a mixed stand of conifers. Their winter roost-sites were distally situated among the most densely-needled branches on the leeward sides of these trees. Heated and unheated taxidermic goldfinch mounts were placed within these sites and at the same height in an adjacent clearing. The radiative and convective characteristics of these locations were monitored simultaneously and compared to predicted power requirements of live goldfinches (based on laboratory calibration of heated mounts) and operative temperatures $\left(T_{e}\right.$; based on body temperatures of unheated mounts). The winter roost-sites significantly reduced radiative and convective heat exchanges between goldfinches and the environment. Based on body composition data for winter goldfinches, all but two birds sampled could endure a 15-h roost period at average overnight $T_{e}$ 's as low as $-40^{\circ} \mathrm{C}$. In contrast, if these birds were prevented from feeding the following day, only $30 \%$ could survive the imposition of a $39-\mathrm{h}$ fast at average $T_{e}$ 's of $-2^{\circ} \mathrm{C}$. Winter roost-site selection may be more constrained by thermoregulatory considerations in small birds than in larger species.
\end{abstract}

The annual variation of solar declination profoundly affects the thermal regimes of north temperate latitudes. Dirunal birds wintering in these regions are confronted with low temperatures, short daylengths and diminishing food availability. Under such conditions, selection of energetically favorable microhabitats would facilitate their maintenance of material and energy balance. Such behavior would be especially important during roosting, an activity that occupies a major fraction of the winter day and occurs when air and radiative temperatures are often at their lowest daily values. However, quantitative estimates of avian roosting expenditure indicate that winter birds may select sites for reasons other than energy conservation. Measurements of air temperatures within a roost and adjacent foraging areas suggested that the energy savings afforded by roost-sites selected by starlings (Sturnus vulgaris; Yom-Tov et al. 1977) and jackdaws (Corvus monedula; Gyllin et al. 1977) were exceeded by flight costs for the majority of birds in reaching

\footnotetext{
* Present address and offprint requests to: School of Zoology, The University of New South Wales, Kensington, New South Wales, Australia 2033
}

these sites. Although it may be argued that these studies lacked thorough meteorological appraisal, investigations that included radiative and convective characteristics revealed that winter-roosts used by starlings minimize energy exchange with the environment (Kelty and Lustick 1977), whereas robins (Turdus migratorius) did not select the energetically most favorable microhabitats available to them (Walsberg and King 1980).

These studies raise questions concerning the extent to which energetic considerations affect winter roost-site selection. However, it is important to note that all the aforementioned birds have body masses exceeding 70 grams. Although all diurnally-active birds are confronted with a protracted nightly fast during the winter, allometric analysis (Calder 1975) and empirical evidence (Kendeigh 1945) demonstrate that avian fasting endurance increases with body mass, with relative survival times of larger versus smaller birds becoming more pronounced as temperature is lowered. Additionally, the inverse relation between forced-convective heat transfer and body diameter (Mitchell 1976) will add to the energetic liability of small size under conditions of wind. Thus, although all birds will derive energy savings by selecting roost-sites that restrict convective and radiative losses of heat to the environment, such considerations may more importantly influence choice of winter roosts by small birds.

American goldfinches are among the smallest birds that regularly overwinter in southern Michigan. Previous studies concerning seasonal acclimatization in members of this population indicate that their primary adjustment to winter involves a substantial increase in thermogenic capacity with relatively minor improvement in insulative quality (Dawson and Carey 1976; Carey et al. 1978). Although such acclimatization permits winter goldfinches to remain euthermic over a broader range of temperatures than at other seasons (Dawson and Carey 1976), it does little to reduce their thermoregulatory costs. Whether these birds behaviorally reduce their nocturnal energy requirements through microhabitat selection is the subject of this investigation.

\section{Material and methods}

Study area

A roost-site being used by American goldfinches was discovered in mid-January 1978, approximately $8 \mathrm{~km}$ north of Ann Arbor, Michigan (latitude $42^{\circ} 20.4^{\prime} \mathrm{N}$, longitude 
$\left.83^{\circ} 45.2^{\prime} \mathrm{W}\right)$. The sites selected by these birds were located in two densely-needled Colorado blue spruce (Picea pungens) which comprised part of a mixed-stand of conifers (3 spp. of Picea, $2 \mathrm{spp}$. of Pinus, and 1 sp. of Pseudotsuga). The trees had been planted in three rows and surrounded all but the south side of a private residence. Roosting behavior was observed on six occasions between 17-30 January 1978. Micrometeorological data were collected at this site from 19 February through 4 March 1978.

\section{Wind measurement}

Wind speed was measured using hot-ball anemometers (see Buttemer 1981; Chappell and Bartholomew 1981 for details). All anemometers were calibrated in a laminar-flow wind tunnel using a Gill 4-vane anemometer (R.M. Young Co.) as a reference. Four anemometers were attached to a thin-walled conduit support and placed in an open field, $12 \mathrm{~m}$ east of the conifer plantation, at heights of $0.5,1.0$, 2.0 , and $5.0 \mathrm{~m}$ above the substrate. Wind speeds within the roost area were obtained by placing anemometers at desired locations and securing the anemometer frames and leads to adjacent branches. Wind direction was monitored with a wind vane positioned $5 \mathrm{~m}$ above the substrate at a site adjacent to the anemometer tower. The vane was attached to a continuous-turn potentiometer which served as part of a voltage divider. The output signal from a constant input voltage provided to this assembly was recorded to monitor wind direction.

\section{Atmospheric thermal radiation}

Total incoming radiation was measured with Fritschen-type net radiometers (Micromet, Inc.) which were fitted with black-body references on their lower hemispheres. The references were fashioned from thermally-insulated aluminum cups which were coated with a flat black paint (Nextel Velvet 101) on all interior surfaces. Thermocouples affixed to the cups' lower surfaces permitted temperature recording. One of these modified radiometers was placed near the anemometer tower at the exposed-site $(1.5 \mathrm{~m}$ above the substrate) and the other was placed in a roost-site located in one of the spruce trees ( $2.2 \mathrm{~m}$ above the substrate).

\section{Temperature measurement}

Air temperature $\left(T_{a}\right)$, substrate temperature $\left(T_{\mathrm{g}}\right)$, and body temperatures of taxidermic mounts (see below) were measured with thermocouples. The junctions of the substrate thermocouples were ensheathed with paper tape and appressed to the substrate (snow at both locations) by packing snow along a $1 \mathrm{~m}$ length posterior to their tips. The latter temperatures were periodically compared with readings from an infrared thermometer (Barnes PRT-10L). Dew point temperature was monitored at a site $2 \mathrm{~m}$ above the substrate with an aspirating hygrometer (Cambridge Systems EG \& G model 880).

\section{Estimates of energy expended by roosting goldfinches}

Any attempt to evaluate the physiological significance of roost-site selection requires both quantification of pertinent micrometeorological variables in the roost and knowledge of their effects on energy expenditure by the animal under study. For a resting endotherm, steady-state energy exchange between the animal and its environment may be expressed as (Bakken and Gates 1975; Bakken 1976):

$$
M-E=K_{e}\left(T_{b}-T_{e}\right)
$$

For an animal maintaining body temperature, net metabolic heat production [total metabolic heat production $(M$ in $\mathrm{W}$ animal ${ }^{-1}$ ) less evaporative heat loss ( $E$ in W animal $\left.{ }^{-1}\right)$ ] must balance heat flow between the animal and its environment. This net heat flux is the product of the animal's overall thermal conductance $\left(K_{e}\right.$ in $\mathrm{W}^{\circ} \mathrm{C}^{-1}$ ani$\mathrm{mal}^{-1}$ ) and the temperature difference between its core body temperature $\left(T_{b}\right.$ in $\left.{ }^{\circ} \mathrm{C}\right)$ and the operative temperature $\left(T_{e}\right.$ in $\left.{ }^{\circ} \mathrm{C}\right)$ experienced by the animal in a particular environment. The latter variable represents the instantaneous equilibrium body temperature that would follow cessation of endogenous heat production $(M)$ and evaporative heat loss $(E)$. This value is influenced by both properties of the animal (e.g., size, shape, color, and distribution of insulation) and those of the environment (e.g., air temperature, wind speed, and radiant characteristics). As a consequence, $T_{e}$ may be quantified by recording the temperature of an object sharing the physical qualities of the animal under study. To this end, American goldfinch taxidermic mounts were constructed by covering hollow copper castings of each animal's body, in its roosting posture, with its integument. In addition, each mount was provided with an internal heater circuit through placement of electrical resistance wire within its bilayer copper body (Bakken et al. 1981; Buttemer 1981).

Thus, $T_{e}$ in a general environment can be gauged by recording body temperatures of unheated mounts and net metabolic heat production can be inferred from the electrical power required to maintain body temperatures of heated mounts equal to those of live birds. However, as vasomotor and ptilomotor adjustments of $K_{e}$ are absent in the mounts, power requirements of mounts versus live birds will likely differ for a given environmental condition. To assess this relation, net metabolic heat production and core body temperatures of winter-acclimatized American goldfinches were measured over a range of operative temperatures $(5$ to $-15^{\circ} \mathrm{C}$ ) and wind speeds $\left(0.15\right.$ to $\left.1.5 \mathrm{~ms}^{-1}\right)$ (Buttemer 1981). Following these determinations, each taxidermic mount was calibrated by recording the electrical power $(P)$ required to maintain its $T_{b}$ at $37^{\circ} \mathrm{C}$ for the same conditions attending the physiological measurements. Comparison of $P$ versus net metabolic heat production of live birds displayed a consistent relation which permitted appraisal of $M-E$ (Eqn. 1) from $P$ of each mount to within $\pm 3 \%$ of actual metabolic measurements (Buttemer 1981).

In evaluating the energy savings afforded by roost-site utilization, power requirements of heated taxidermic mounts and attendant wind speeds were monitored at a frequently used roost-site in one of the spruce trees $(2.2 \mathrm{~m}$ height) and at a location $14 \mathrm{~m}$ to the east in an open field ( $2 \mathrm{~m}$ height). The former location was subtended by several other spruce branches and was covered by a branch laden with approximately $5 \mathrm{~cm}$ of snow. Operative and radiant sky temperatures were determined from unheated taxidermic mounts and modified net radiometers, respectively. One of each was placed within a separate roost-site of the same height and configuration as the one containing the heated mount and, likewise, at a location adjacent to the exposed heated mount. 


\section{Results}

\section{Roosting behavior}

Goldfinches tended to arrive at the roosting area $45-75 \mathrm{~min}$ before dusk, sometimes in the company of other cardueline finches. On each occasion, a few birds would perch in nearby oaks (Quercus spp.) and periodically call to goldfinches in flight. The largest pre-roosting assemblage observed consisted of 12 individuals (9 Carduelis tristis; $3 \mathrm{C}$. flammea), while the smallest contained 3 (C. tristis). Before entering the roost, all birds fed on catkins of nearby birch trees (Betula sp.). The birds would commonly leave the area en masse, flying in a large circle (ca. $150 \mathrm{~m}$ ) around the roost area, and then return to the birches and oaks. Approximately $15-30 \mathrm{~min}$ before dusk, the entire group flew silently to the crowns of the two Colorado blue spruce. When I approached these trees 30 -min later, the birds flushed from branches $2-3 \mathrm{~m}$ above the substrate. The roost-sites selected by birds, which I found by inspecting the branches for excreta, were located near the ends of branches along the $S$ and SE sides of the two trees. Morning departures were not observed directly, but no birds were seen at the roost area $30 \mathrm{~min}$ after sunrise.

\section{Thermoregulatory significance of roost-site utilization}

The extent to which the sites selected by birds reduce their energy exchange with the environment is revealed by comparing measurements taken at exposed- versus roost-sites (Figs. 1-3). The greatest difference in power requirements at these sites occurred on the night of 28 February (Fig. 1). Although the sky was particularly overcast for most of that evening, as indicated by similar operative, air, and radiant sky temperatures, a protracted period of wind (ca. 2200-0515) resulted in a marked increase in power requirements outside the roost. Wind speeds during this interval averaged $3.2( \pm 0.1)$ and $0.1( \pm 0.01) \mathrm{m} \mathrm{s}^{-1}$ outside and within the roost, respectively. Owing to these differing convective regimes, power requirements at the exposed location were $31 \%$ greater for this interval than those within the roost. Given the near equality of $T_{a}$ and $T_{e}$ at both sites (Fig. 1), the need to include considerations for convective heat transfer when evaluating roost-site quality is clearly indicated.

Another means by which roost-site occupancy confers energy savings is indicated by data gathered the following evening (1-2 March; Fig. 2). Although air movements outside the roost were relatively calm, averaging $0.3 \mathrm{~m} \mathrm{~s}^{-1}$, the predicted energy expenditures were $10.6 \%$ greater at this location than within the roost. The combination of extended periods of clear sky (note radiant sky temperatures in Fig. 2) and low wind speed resulted in exposed $T_{e}$ 's averaging $4.7^{\circ} \mathrm{C}$ lower than those in the roost. The relative opacity of the roost-site to thermal exchanges with the night sky is revealed by comparison of overhead radiant temperatures at the two sites (Table 1). Even with radiant sky temperature averaging over $25^{\circ} \mathrm{C}$ lower than air temperature, radiant temperatures within the roost did not differ significantly from air temperature at this site.

Measurements taken 34 March demonstrate the combined effects of wind and radiation on operative temperature (Fig. 3). During periods of low wind and clear sky, $T_{e}$ at the exposed-site diverged from that at the roost. The

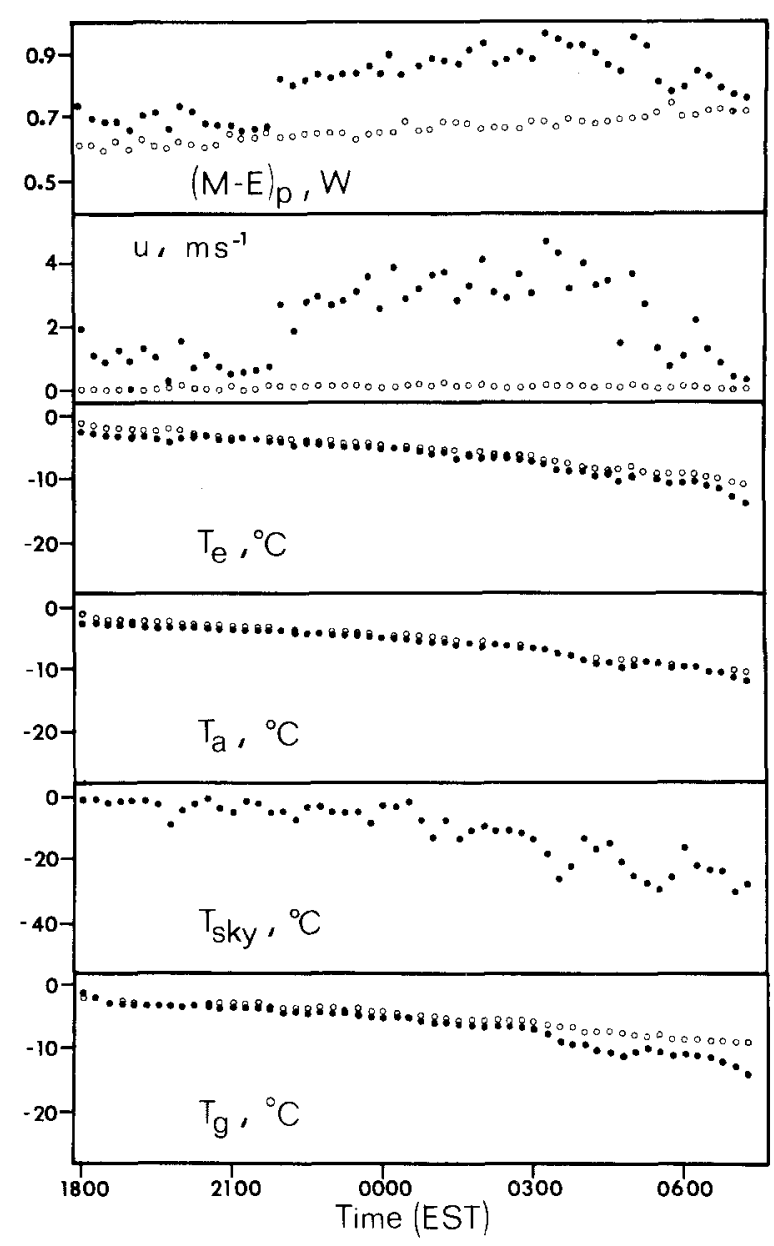

Fig. 1. Micrometeorological measurements and predicted power requirements $\left(M-E_{P}\right)$ of life goldfinches at a roost-site (o) and an exposed site $(\bullet)$ for 28 February-1 March. Wind speed $(u)$ and air temperature $\left(T_{a}\right)$ were measured $2 \mathrm{~m}$ above the substrate at the exposed location. Operative temperatures $\left(T_{e}\right)$ and predicted power requirements were obtained from heated and unheated taxidermic mounts, respectively. $T_{g}$ represents substrate surface temperature and $T_{s k y}$ is the atmospheric radiant temperature

relatively moderate wind and radiation regimes of this night (cf. Figs. 1 and 2, respectively) resulted in power requirements averaging $12 \%$ greater outside versus inside the roost.

In estimating total metabolic expenditure from predictions of net metabolic heat production, knowledge of the birds' rate of evaporative water loss is required. The similarity of air vapor densities for the field study to those of the laboratory metabolic measurements $(0.9$ to 1.7 versus 1.1 to $1.3 \mathrm{~g} \mathrm{~m}^{-3}$, respectively) permits estimation of evaporative heat loss accompanying these outdoor conditions. Combining these values with the predicted power requirements and integrating the results over time yields an estimate of the total energy expended by goldfinches roosting under these conditions. In comparing these values, and the meteorological measurements accompanying them (Table 1), it is apparent that goldfinch winter roost-sites are very effective in restricting radiative and convective exchanges of heat with the environment. However, goldfinches benefitted most from their roost occupancy during periods of wind. In this regard, the measurements taken at the exposed-site may underestimate the actual savings 


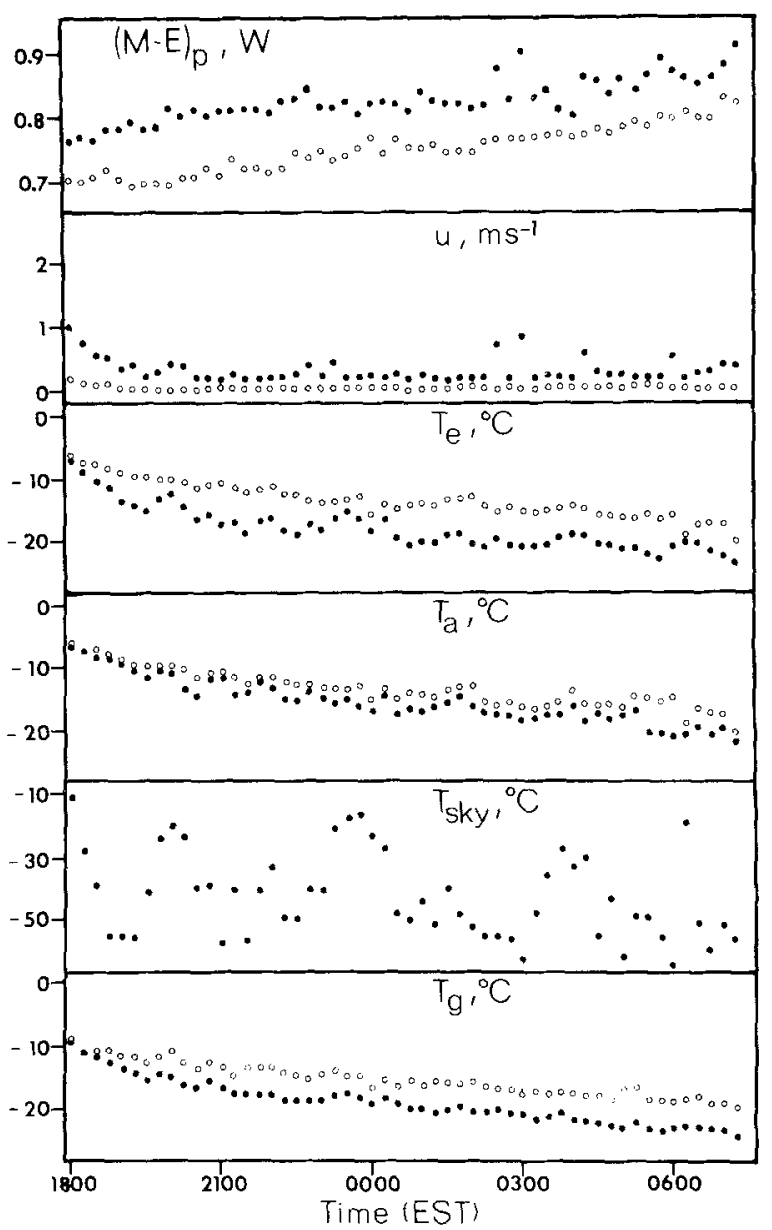

Fig. 2. Micrometeorological measurements and predicted power requirements of live goldfinches for 1-2 March. Locations of measurement, abbreviations, and symbols described in Fig. 1

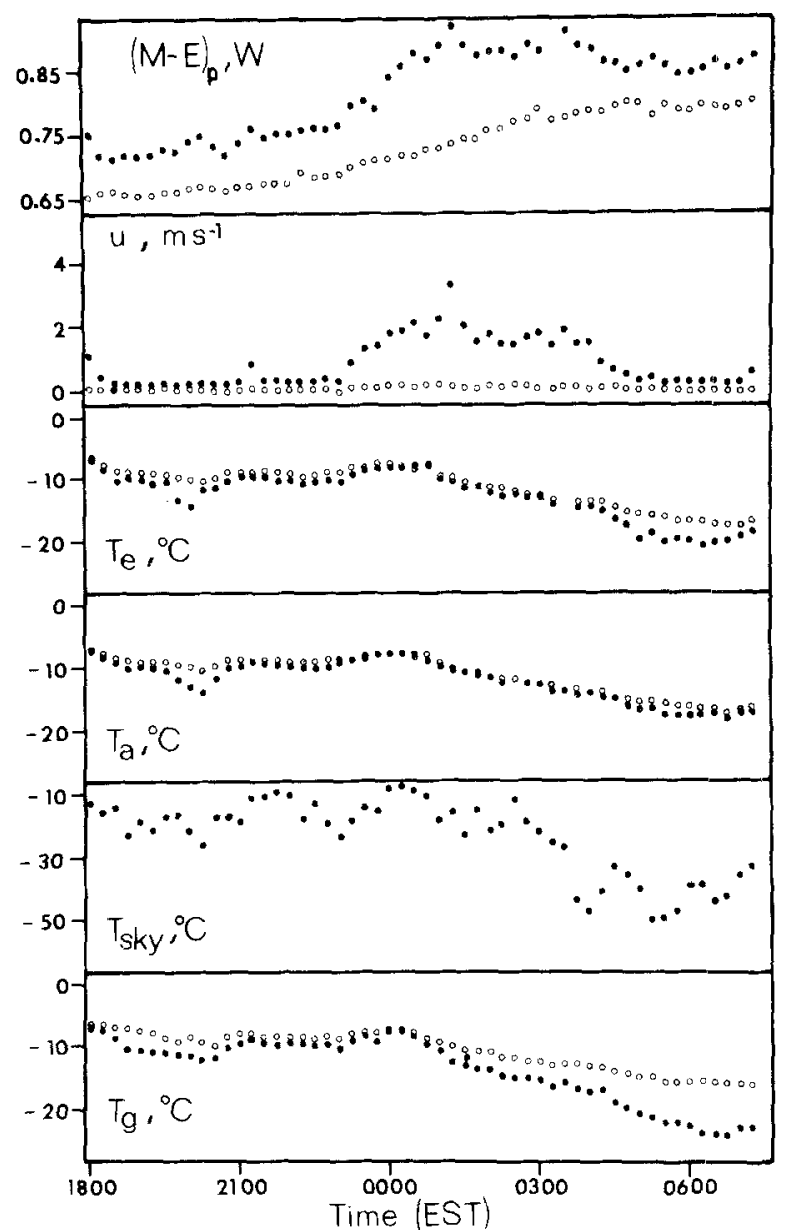

Fig. 3. Micrometeorological measurements and predicted power requirements of live goldfinches for 2-3 March. Locations of measurement, abbreviations, and symbols described in Fig. 1

Table 1. Predicted energy expenditures of live goldfinches and overnight averages of meteorological conditions at exposed- versus roost-sites for three consecutive roost periods

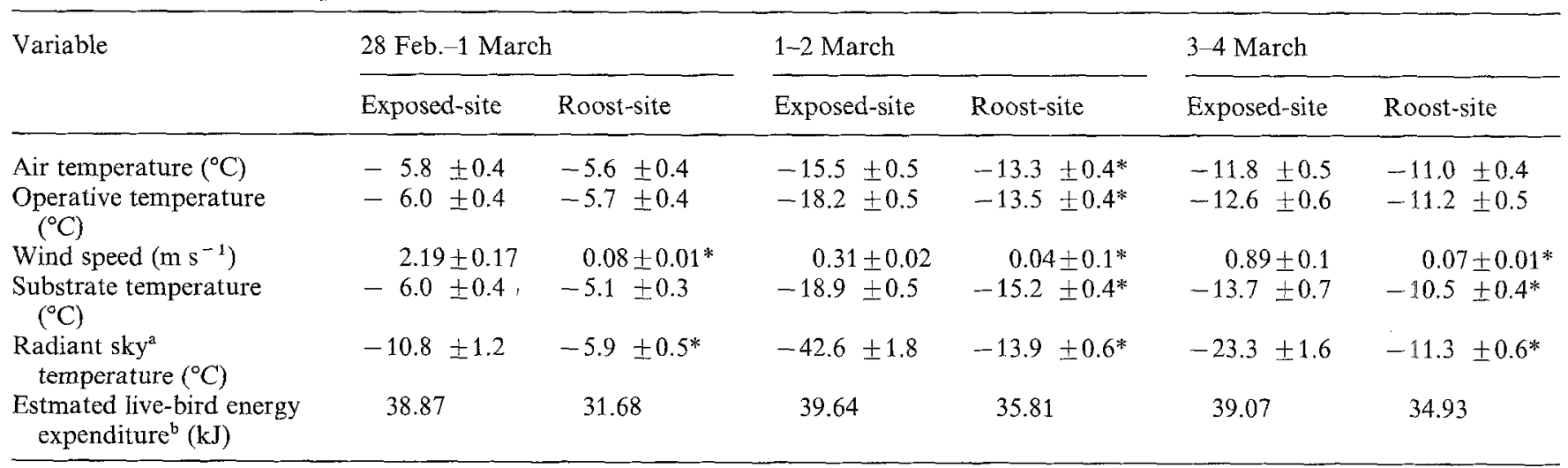

a Radiant sky temperature at the roost-site represents the radiant temperature of the foliage above the roost-site

$b$ Estimate includes predicted evaporative heat loss (see text) and represents a $13.5 \mathrm{~h}$ roost-period

* Variables which differ significantly between the two sites $(P \leq 0.01)$

attending roost utilization. During the period of high northwesterly wind (Fig. 1), the exposed-site was in a partial lee. Wind speeds measured at a clearing $20 \mathrm{~m}$ north of the conifer stand averaged $4.9 \mathrm{~m} \mathrm{~s}^{-1}$ versus a concommitant mean of 0.1 and $3.2 \mathrm{~m} \mathrm{~s}^{-1}$ at the roost- and exposed-sites, respectively.

\section{Discussion}

\section{Roost-site selection}

The energy cost of roosting is comprised of a bird's metabolic expenditures during roost-site occupancy plus its loco- 
motory costs in traveling to and from foraging areas. Thus, the energy required for roosting depends importantly on the roost-site's location, both in terms of its distance from feeding-sites as well as its micrometeorological qualities. The winter roost-sites selected by American goldfinches conferred energy savings to them by both criteria. In addition to the roost's proximity to food sources, the physical qualities of their roost-sites significantly lowered their potential losses of heat to the environment (Figs. 1-3; Table 1). While occupancy of these sites promoted energy savings for all conditions studied, the energetic benefits derived from their use were greatest during periods of wind (Fig. 1; Table 1). The fact that goldfinches restricted their roosting to sites on the leeward side of the most densely-needled trees in the conifer stand supports the argument that thermoregulatory concerns play an important role in their choice of roost-sites.

This contrasts with the situation observed in wintering American robins (Walsberg and King 1980). The latter study found that the most favorable microhabitats within a fir grove (Pseudotsuga menziesii) were sites immediately adjacent to tree trunks. These were not used by robins, which instead roosted on branches 1-2 $\mathrm{m}$ away. Walsberg and King (1980) suggested that birds using these locations might better be able to detect and escape predation than if they chose locations close to the trunk (Walsberg and King 1980). If this were true, the distal location of sites selected by goldfinches should confer a similar degree of protection from predators.

In assessing the meteorological quality of sites not used by goldfinches, two heated taxidermic mounts were placed in locations shielded from wind but visible upon close approach. One of the mounts was located on a leeward branch of an European black pine (Pinus nigra) ( $3 \mathrm{~m}$ height) and the other was positioned $0.3 \mathrm{~m}$ interior to the eastern edge of the grove in a Douglas fir (Pseudotsuga menziesii) $(0.3 \mathrm{~m}$ height). Predator presence became apparent one afternoon when both of these mounts displayed unusually high power requirements. Upon inspection, both mounts were missing most of their skin and feathers. In contrast, none of the mounts placed at goldfinch roost-sites were similarly disturbed.

These observations suggest that selection of roost-sites for purposes of reducing both energetic expenditure and predator detection are not mutually exclusive. In this context, it is puzzling that robins selected sites attended by windspeeds over an order of magnitude greater than those measured at goldfinch roost-sites during similar external conditions. Assuming that the sites selected by both species afford a similar degree of predator protection, thermoregulatory considerations are apparently a less important feature of roost-site selection by these larger birds $(75 \mathrm{~g})$ than for goldfinches $(14.5 \mathrm{~g})$. Some insight into this situation is provided by comparing available measurements of wind effects on nocturnal metabolic heat production of passerines (Fig. 4). In viewing these relations, energy expenditure increases directly with wind for all three species, but the magnitude of this effect is inversely related to their body size (Fig. 4). When evaluated in the context of overnight energy requirements, the cost of roosting $15 \mathrm{~h}$ at $0^{\circ} \mathrm{C}$ with windspeeds of $0.1 \mathrm{~m} \mathrm{~s}^{-1}$ is equivalent to an amount of body lipid representing $2.5,4.8$, and $6.1 \%$ of the starlings', whitecrowned sparrows', and goldfinches' body masses, respectively. At windspeeds of $4 \mathrm{~m} \mathrm{~s}^{-1}$, these values increase to

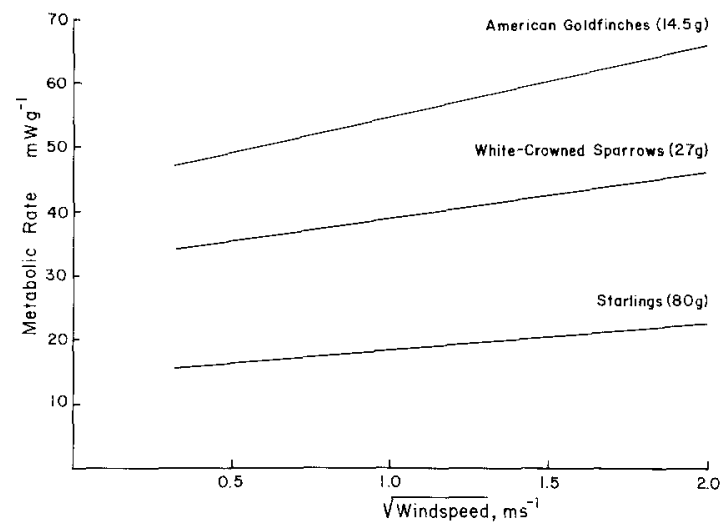

Fig. 4. Metabolic heat production at $0^{\circ} \mathrm{C}$ air temperature as a function of wind speed. Data for goldfinches after Buttemer (1981), white-crowned sparrows after Robinson et al. (1976), and starlings after Kelty and Lustick (1977)

$3.1,6.5$, and $8.6 \%$, respectively, for the same three species. This demonstrates that the energetic liabilites noted for small birds exposed to low temperatures (Kendeigh 1969) are further exacerbated by conditions of wind. Bearing in mind that the extent of mass-specific hibernal fattening is similar in these birds (Blem 1981; Carey and Dawson 1978; King and Farner 1966), smaller birds may have a greater energetic incentive to select wind-protected roosts than larger forms. It must be emphasized, however, that all birds will derive energetic benefits through use of such sites.

\section{Estimates of roosting endurance}

For birds residing in north-temperate regions, the combination of long nights and low temperatures elevate their roosting costs to their highest annual level. Small birds wintering in cold climates commonly display significant increases in storage lipids during this period (King 1972; Blem 1976). This fattening results from adaptive hyperphagia (King 1961) and appears to be proximately cued by photoperiod (Evans 1969). Members of the goldfinch population under study share this pattern of enhanced lipogenesis during winter (Carey et al. 1978). From analysis of body composition, the average fat content of 27 individuals captured between 1400-1500 EST during the winter of 1977-1978 was $1.77 \pm 0.09 \mathrm{~g}$ (range $=0.66$ to $2.58 \mathrm{~g}$; Dawson and Marsh MS). Assuming a thermal equivalent of $38.5 \mathrm{~kJ} \mathrm{~g}^{-1}$ for lipid (Johnston 1970) and that $0.1 \mathrm{~g}$ of this fat is unavailable for thermogenic needs (Newton 1969), the effect of temperature on the ability of these birds to endure a $15-\mathrm{h}$ period of roosting can be evaluated.

For this estimate, all birds are presumed to ingest $1.0 \mathrm{~g}$ dry mass of birch seed before entering the roost, with a metabolizable energy value of $16.1 \mathrm{~kJ} \mathrm{~g}^{-1}$ dry mass (Kendeigh and West 1965; Brooks 1968). Similar amounts of seed were found in several winter goldfinches collected at midafternoon (R.L. Marsh, pers. comm.). Roosting energy expenditures are based on metabolic measurements of winter-acclimatized goldfinches under conditions of wind (Buttemer 1981) and assume an average wind speed of $0.1 \mathrm{~m} \mathrm{~s}^{-1}$ at the roost-site (Table 1). With these criteria, of the 27 birds, 26 could sustain euthermic levels of metabolism at average operative temperatures as low as $-25^{\circ} \mathrm{C}$ and all but 2 could endure a $15-\mathrm{h}$ exposure to $T_{e}=-40^{\circ} \mathrm{C}$. 
As these average overnight temperatures are much lower than those normally occurring in this region, most goldfinches wintering in Ann Arbor contain energy reserves in excess of their overnight roosting requirements.

Similar findings are reported for other small passerines (summarized by King 1972; but see Blem 1984), but the extent of their winter fattening is generally insufficient to permit fasting beyond the following day. To evaluate whether wintering goldfinches must feed daily, the energy reserves of the goldfinches described above can be compared to estimates of roosting costs for two nights and one day over a range of temperatures. As a first approximation, birds are presumed to maintain euthermic levels of metabolism for two 15-h nocturnal roost periods separated by a 9-h diurnal phase. Lacking daytime measurements, diurnal expenditures are inferred from comparison of dayversus night-metabolic determinations of a closely-related cardueline finch (Carduelis flammea; Pohl and West 1973). Again goldfinches are presumed to enter the roost the first evening with $1 \mathrm{~g}$ dry seed and to remain there for the entire $39 \mathrm{~h}$ with average wind speeds of $0.1 \mathrm{~m} \mathrm{~s}^{-1}$.

Based on the lipid reserves of the 27 goldfinches referred to above, 3 of these birds could endure this 39-h fast at $T_{e}=-5^{\circ} \mathrm{C}$ and only 1 at $T_{e}=-10^{\circ} \mathrm{C}$. However, the environmental conditions most likely to prevent diurnal feeding are excessive snowfall and ice storms. As both of these events are associated with temperatures close to or slightly below $0^{\circ} \mathrm{C}$ (D.L. Baker, pers. comm.), approximately $30 \%$ of these goldfinches could survive a $39-\mathrm{h}$ fast at $T_{e}=-2^{\circ} \mathrm{C}$. Although unlikely, if either of these events were to prevent goldfinches from feeding for an entire day, most of the birds would perish. This assumes, of course, that the estimates of energy stores and power requirements used for these calculations accurately reflect those of goldfinches fasting under such conditions. In this context, the assignment of euthermic levels of metabolism for the full $39 \mathrm{~h}$ will overestimate roosting costs if goldfinches display hypothermia during this period. Although winter-acclimatized goldfinches have been reported to conserve energy through nocturnal hypothermia (Lustick et al. 1982), these results are difficult to reconcile with measurements obtained from Michigan birds (Dawson and Carey 1976; Buttemer 1981). The body temperatures recorded for goldfinches exposed to $0^{\circ} \mathrm{C}$ are approximately $6^{\circ} \mathrm{C}$ lower in the former than those of the latter studies, whereas the metabolic rates differ by less than $2 \%$. Owing to these uncertainties, it appears prudent to restrict evaluation of roosting costs to estimates of euthermic power requirements.

Perhaps of greater concern is the degree to which the energy storage values recorded for winter goldfinches represent those of birds prior to a storm's arrival. Winter birds seldom attain their actual capacity for fat storage, with hibernal values usually representing less than half their potential amount (King 1972). Thus, the extent of lipid accumulation in winter birds appears to represent a dynamic balance between the costs of carrying extra mass and the benefits derived from energy storage (King 1972). If goldfinches could anticipate adverse weather conditions and respond by increasing their energy stores, their chances for survival would be markedly improved. As most winter storms are preceded by rapid changes in atmospheric pressure, anticipatory responses could result from detection of barometric perturbations. Such attributes have been ascribed qualitatively to migrating birds (Keeton 1979) and wintering black-capped chickadees (Parus atricapillus; Lawrence 1958). The latter study noted that chickadees fed voraciously prior to a major temperature drop, apparently in response to a rapid decline in barometric pressure. The ability to detect pressure change was demonstrated quantitatively in pigeons (Columba livia) with 10 of the 12 birds studied demonstrating a $50 \%$ threshold of detection of $10 \mathrm{~mm} \mathrm{H}_{2} \mathrm{O}$ or less (Kreithen and Keeton 1974).

Indirect evidence of atmospheric pressure detection by American goldfinches is furnished by studies of A.L. Middleton of Guelph, Ontario (pers. comm.). An excessively heavy snowfall occurred shortly after noon on 26 January 1978 and was preceded by the lowest barometric pressure ever recorded in Detroit, Michigan (95.95 kPa). Middleton noted that the goldfinches at this trapping station exhibited a frenzied feeding behavior prior to the storm's arrival. Furthermore, birds that he captured on this date had body masses averaging $10 \%$ greater than those normally associated with goldfinches at this season. Although such behavior will undoubtedly increase these birds' roosting endurance, lack of information concerning their body composition restricts evaluation of the extent to which this occurs. However, if the 27 Michigan goldfinches displayed similar increases in mass $(1.5 \mathrm{~g})$ before a storm's arrival, and if this represents $1.0 \mathrm{~g}$ of seed and $0.5 \mathrm{~g}$ of fat, the number of goldfinches able to endure a $39-\mathrm{h}$ fast at 0 and $-5^{\circ} \mathrm{C}$ would increase to 25 and 21 birds, respectively. Clearly, more attention must be paid to the possible influence of anticipatory hyperphagia on the energy balance of goldfinches before any conclusions concerning fasting endurance can be drawn.

Acknowledgements. Support for this study was provided by NSF grants DEB 77-25487 and BSR 80 21389 to W.R. Dawson and NSF grant GB-40980 and AEC contract AT(11-1) to D.M. Gates. Space and equipment were generously furnished by W.R. Dawson, D.M. Gates and W.W. Willmarth. Field and laboratory measurements benefitted substantially from collaboration with G.S. Bakken who also provided the design for field anemometry. T.E. Lahti and R.L. Marsh provided field assistance and L.B. Astheimer, W.R. Dawson, D.M. Gates, M.J. Kluger, and R.B. Payne commented on early drafts of the manuscript. I thank W.R. Dawson, R.L. Marsh, and A.L. Middleton for allowing access to unpublished information.

\section{References}

Bakken GS (1976) A heat-transfer analysis of animals: Unifying concepts and the application of metabolism chamber data to field ecology. J Theor Biol 60:337-384

Bakken GS, Gates DM (1975) Heat-transfer analysis in animals: Some implications for field ecology, physiology, and evolution. In: Gates DM, Schmerl RB (eds) Perspectives of biophysical ecology. Springer, Berlin Heidelberg New York, pp 255-290

Bakken GS, Buttemer WA, Dawson WR, Gates DM (1981) Heated taxidermic mounts: A means of measuring the standard operative temperature affecting small animals. Ecology $62: 311-318$

Blem CR (1976) Patterns of lipid storage and utilization in birds. Am Zool 16:671-684

Blem CR (1981) Geographic variation in mid-winter body composition of starlings. Condor 83:370-376

Blem CR (1984) Mid-winter lipid reserves of the golden-crowned kinglet. Condor 86:491-492

Brooks WS (1968) Comparative adaptations of the Alaskan redpolls to the arctic environment. Wilson Bull 80:253-280

Buttemer WA (1981) The thermal significance of winter roost-site selection by American goldfinches (Carduelis tristis). Ph D dissertation, Ann Arbor, The University of Michigan. 
Calder WA (1974) Consequences of body size for avian energetics. In: Paynter RA (ed) Avian energetics. No. 15, Publ. Nuttall Ornithological Club. Cambridge Massachusetts, pp 86-151

Carey C, Dawson WR, Maxwell LC, Faulkner JA (1978) Seasonal acclimatization to temperature in cardueline finches. II. Changes in body composition and mass in relation to season and acute cold stress. J Comp Physiol 125:101-113

Chappell MA, Bartholomew GA (1981) Standard operative temperatures and thermal energetics of the antelope ground squirrel Ammospermophilus leucurus. Physiol Zool 54:81-93

Dawson WR, Carey C (1976) Seasonal acclimatization to temperature in cardueline finches. I. Insulative and metabolic adjustments. J Comp Physiol 112:317-333

Evans PR (1969) Winter fat deposition and overnight survival of yellow buntings (Emberiza citrinella L.). J Anim Ecol 38: 415-423

Gyllin R, Kallander H, Sylven M (1977) The microclimate explanation of town centre roosts of jackdaws Corvus monedula. Ibis 119:358-361

Johnston DW (1970) Caloric density of avian adipose tissue. Comp Biochem Physiol 34:827-832

Keeton WT (1979) Avian orientation and navigation. Annu Rev Physiol 41:353-366

Kelty MP, Lustick SI (1977) Energetics of the starling (Sturnus vulgaris) in a pine woods. Ecology 58:1181-1185

Kendeigh SC (1945) Resistance to hunger in birds. J Wildlife Manag 9:217-226

Kendeigh SC (1969) Tolerance of cold and Bergmann's rule. Auk $86: 13-25$

Kendeigh SC, West GC (1965) Caloric values of plant seeds eaten by birds. Ecology $46: 553-555$
King JR (1961) The bioenergetics of vernal premigratory fat deposition in the white-crowned sparrow. Condor 63:128-142

King JR (1972) Adaptive periodic fat storage by birds. In: Voous KH (ed) Proc. 15th Ornith Congr, Brill EJ, Leiden, pp 200-217

King JR, Farner DS (1966) The adaptive role of winter fattening in the White-crowned Sparrow with comments on its regulation. Amer Nat 100:403-418

Kreithen ML, Keeton WT (1974) Detection of changes in atmospheric pressure by the homing pigeon, Columba livia. J Comp Physiol 89:73-82

Lawrence $\mathrm{L}$ de $\mathrm{K}$ (1958) On regional movements and body weight of black-capped chickadees in winter. Auk 75:415-443

Lustick S, Battersby B, Mayer L (1982) Energy exchange in the winter acclimatized American goldfinch Carduelis (Spinus) tristis. Comp Biochem Physiol 72 A:715-719

Mitchell JW (1976) Heat transfer from spheres and other animal forms. Biophys J 16:561-569

Newton I (1969) Winter fattening in the bullfinch. Physiol Zool 42:96-107

Pohl H, West GC (1973) Daily and seasonal variation in metabolic response to cold during rest and forced exercise in the common redpoll. Comp Biochem Physiol 45:851-867

Robinson DE, Campbell GS, King JR (1976) An evaluation of heat exchange in small birds. J Comp Physiol 105:153-166

Walsberg GE, King JR (1980) The thermoregulatory significance of the winter roost-sites selected by robins in eastern Washington. Wilson Bull 92:33-39

Yom-Tov Y, Imber A, Otterman J (1977) The microclimate of winter roosts of the starling Sturnus vulgaris. Ibis 119:366-368

Received January 28, 1985 